\title{
3. De nuevo sobre los signos adverbiales de modalidad epistémica que refuerzan la aserción en español actual: propiedades sintácticas y semánticas y comportamiento discursivo
}

María Antonia Martín Zorraquino

Universidad de Zaragoza

\section{Introducción}

En la presente contribución vuelvo sobre un tema del que vengo ocupándome desde hace bastantes años (cf. Martín Zorraquino I993, I994, 200I, 2003, 2010a, 20I0b y 20I3) y que constituye un campo de estudio del que también tratan otros investigadores de la Universidad de Zaragoza con los que me honra colaborar ${ }^{\mathrm{I}}$.

Los elementos de los que voy a tratar forman parte del elenco de los llamados signos adverbiales de modalidad (utilizado el término en su más amplio sentido: cf. n. I). Más en concreto integran un paradigma que incluye unidades como: evidentemente, obviamente, desde luego, naturalmente, por supuesto, claro, claramente, etc. No se trata de un paradigma cerrado. Junto a todos esos signos, se hallan a veces unidades como: ciertamente y verdaderamente, o indudablemente y sin $d u d a$, o efectivamente y en efecto, etc. E incluso elementos como francamente. El motivo por el que todos estos signos se reúnen en un mismo grupo suele radicar en que parecen funcionar de manera afín desde el punto de vista sintáctico y desde el punto de vista semántico-pragmático: todos ocupan una posición marginal o extrapredicativa respecto del conjunto de constituyentes que comentan (es decir, no están integrados dentro de la construcción lingüística a la que remiten -verbal o nominal, habitualmente, pero también de otra índole: cf. infra, ejs. I a 6-), todos refuerzan la verdad del segmento discursivo aludido y, en el caso de que sean adverbios en -mente, son signos que guardan relación con adjetivos que califican algo como ajustado a la verdad o a la percepción

Cómo citar este capítulo:

Martín Zorraquino, María Antonia, De nuevo sobre los signos adverbiales de modalidad epistémica que refuerzan la aserción en español actual: propiedades sintácticas y semánticas, y comportamiento discursivo. In: Engwall, Gunnel \& Fant, Lars (eds.) Festival Romanistica. Contribuciones lingüísticas - Contributions linguistiques - Contributi linguistici Contribuições linguísticas. Stockholm Studies in Romance Languages. Stockholm: Stockholm University Press. 20I 5, pp. 37-63. DOI: http://dx.doi.org/Io.I6993/bac.c. License: CC-BY 
que se tiene de ello (cierto, verdadero, veraz, claro, evidente, etc., para, por ejemplo, una noticia cierta, una información verdadera o veraz, un problema claro, un resultado evidente, una propuesta franca, etc.).

Pero, a pesar de sus aparentes afinidades, los signos adverbiales que acabo de mencionar no son homogéneos desde el punto de vista sintáctico. Y presentan también algunas diferencias respecto de sus propiedades semánticas, pese a su real proximidad significativa (y pragmática). Por ello, me ha parecido oportuno centrarme en algunos de los rasgos que los caracterizan. Voy a analizar, así, ciertos aspectos de: a) sus propiedades sintácticas; b) sus rasgos semánticos; c) la proyección pragmática que dichos rasgos manifiestan en el discurso. Especialmente, trataré de abordar un pequeño conjunto de cuestiones problemáticas que suscita el análisis de dichos elementos y que preciso a continuación. Desde el punto de vista semántico-pragmático: I) ¿constituyen signos propiamente integrables dentro de la clase funcional de los marcadores discursivos?, o, dicho de otra manera: ¿en qué medida su significado puede ser considerado de procesamiento, en el marco, por ejemplo, de la Teoría de la Relevancia (Sperber / Wilson I986); y 2) ¿qué afinidades y diferencias presenta el paradigma de signos adverbiales que aquí destacamos con el de los adjetivos cuya base léxica coincide con la suya (cierto, verdadero, claro, evidente, etc.)? Desde el punto de vista más propiamente informativo: 3) siendo unidades disjuntas, pueden ocupar posiciones incidentales al inicio, en medio o al final del enunciado al que remiten, pero ¿qué repercusión alcanzan dichas diferencias distribucionales en el nivel informativo del análisis?; 4) ¿le impone algún tipo de condicionamiento a dicha versatilidad distribucional la linealidad del significante que determinó F. de Saussure (I9I6) como propiedad del signo lingüístico? Son muchas preguntas. Intentaré, no obstante, contestar a ellas aunque no lo haga de modo exhaustivo, pues no me ocuparé de todos los signos mencionados ni contestaré de forma minuciosa a todas las cuestiones expuestas. Lo que voy a intentar ofrecer, como respuesta, es una propuesta, con base en el análisis de algunos de los elementos citados, que pueda servir de "pista" para aplicarse al resto.

\section{Propiedades sintácticas}

Es Barrenechea (I979 [I969]) quien denomina, a los elementos de que tratamos, "reforzadores de la aserción", en el sentido de que la intensifican o la enfatizan, confirmándola en el enunciado en el que 
comparecen. Pongamos algunos ejemplos para ilustrar la función semántico-pragmática que señalamos.

Supongamos que Juan, que es un niño muy travieso, ha roto, de nuevo, con el balón, el cristal de la ventana del cuarto donde está su madre. La mamá bien puede decirle a Juan los enunciados que siguen (especialmente, los incluidos de I a 6) o bien puede emitir, reflexionando consigo misma -o dirigiéndose a otra persona-, los marcados de (I)' a (6)':

(I) Ciertamente, eres incorregible

(I)' Ciertamente, un niño incorregible / Ciertamente, incorregible

(2) Verdaderamente, eres incorregible

(2) Verdaderamente, un niño incorregible / Verdaderamente, incorregible

(3) Evidentemente, eres incorregible

(3)' Evidentemente, un niño incorregible / Evidentemente, incorregible

(4) Obviamente, eres incorregible

(4)' Obviamente, un niño incorregible / Obviamente, incorregible

(5) Desde luego, eres incorregible

(5)' Desde luego, un niño incorregible / Desde luego, incorregible

(6) Francamente, eres incorregible

(6) Francamente, un niño incorregible / Francamente, incorregible

Teniendo en cuenta los ejemplos que acabamos de ofrecer, parece que nos encontremos ante signos adverbiales intercambiables y muy próximos en su significado y en su proyección pragmática. Sin embargo, a pesar de sus aparentes afinidades, los elementos adverbiales expuestos no son homogéneos desde el punto de vista sintáctico. En relación con el conjunto de ejemplos propuesto, francamente no se comporta exactamente como los demás. Sintácticamente, siguiendo la clasificación ya clásica de Sidney Greenbaum (I969), que determinó una renovación importante en los estudios sobre los adverbios en muchas lenguas, entre ellas, las románicas, francamente sería un disjunct of style o disjunto de estilo. Es decir, con variaciones terminológicas, según las lenguas, un adverbio enunciativo.

Así, en el seno de la gramática española, la Real Academia Española y la Asociación de Academias de la Lengua Española (2009: $\mathbb{3}$ 30.10) (en adelante, NGLE) lo denominan adverbio oracional de la enunciación o del acto verbal, mientras que, a los restantes signos adverbiales (adverbios o locuciones adverbiales) mencionados, los etiquetan como adverbios oracionales del enunciado (y más concretamente, a tenor de sus propiedades semánticas, los incluyen en el subgrupo de evidenciales) ${ }^{2}$. 
En la gramática funcional de Dik (I997) se diferencian también ambos grupos de adverbios: los llamados adverbios oracionales enunciativos se incluyen en el nivel o estrato superior del análisis de la estructura oracional (nivel 4), mientras que los llamados adverbios oracionales del enunciado se incluyen en el inmediatamente más bajo (nivel 3); a los primeros, Dik los considera disjuncts of style, y a los segundos, attitudinal disjuncts (y el propio Dik reconoce que adopta la terminología y la caracterización de Greenbaum). En efecto, Greenbaum (I969) determina claramente las diferencias entre una y otra clases de adverbios. Los que pertenecen al grupo de francamente (los enunciativos) pueden combinarse con todas las modalidades oracionales (asertiva, imperativa, interrogativa). Así, volviendo a los ejemplos de la madre disgustada con el pequeño Juan, esta podría decirle no solo lo que le ha dicho en el ejemplo (6), sino también:

(7) Francamente, ¿cuándo vas a dejar de ser tan bruto?

(8) Francamente, pórtate bien y no rompas más cristales

En cambio, parece que resultaría más raro que la mamá le dijera a Juan algo como:

(9) ?Obviamente, ¿cuándo vas a dejar de ser tan bruto?,

o como:

(го) ?Evidentemente, pórtate bien y no rompas más cristales,

a no ser que, antes de proferir los enunciados incluidos en (9) o en (Io), ella u otra persona hubieran emitido ya, respectivamente, la pregunta incluida en (7) o la orden reflejada en (8). En esos casos, se mostraría, con (9), la obviedad de la necesidad de plantear la pregunta formulada o, en el caso de (Io), lo evidente de la necesidad de dar (y cumplir) la orden proferida. Es decir, tanto en (9) como en (10), el empleo de los adverbios con una oración interrogativa o imperativa reflejarían un comentario en cierto modo metalingüístico, pues remitirían a una pregunta o a una orden ya formuladas (Martín Zorraquino I994; $c$. Jackendoff I972 y Bellert I977).

En Greenbaum (I969) se recogen con precisión las propiedades que distinguen a los adverbios de la enunciación de los adverbios del enunciado (disjuntos de estilo y disjuntos de actitud, respectivamente). La distinción se viene practicando en los trabajos sobre los adverbios llamados oracionales en muchas otras lenguas ${ }^{3}$. Dicho esto, 
quiero destacar también que, a pesar de las diferencias que separan a los adverbios disjuntos enunciativos de los actitudinales, no siempre es fácil establecer distinciones netas entre ambos conjuntos de signos. Las afinidades semánticas son a menudo muy estrechas (los ejemplos expuestos lo prueban, y podríamos recordar más propiedades comunes), y las funciones discursivas que ambos grupos pueden desempeñar son muy parecidas. El carácter extrapredicativo (marcado habitualmente por pausa o pausas en la entonación, y por medio de coma o comas en la escritura) de unos y otros signos adverbiales facilita que se los analice o se los estudie conjuntamente; así como el hecho de que ambas clases de adverbios suelan considerarse vinculadas con el concepto de subjetividad o con la noción de la expresión de la actitud del hablante (es decir: la modalidad de la enunciación y la modalidad del enunciado). De hecho, la NGLE, por ejemplo, reconoce que, no solo a los llamados adverbios oracionales de la enunciación y a los llamados adverbios oracionales del enunciado, sino también a los adverbios y locuciones adverbiales de tipo conectivo (como, por ejemplo, consecuentemente o por consiguiente), se los denomina y engloba, conjuntamente, bajo la etiqueta de adverbios periféricos (op. cit., $\mathbb{S} 30.10$ ). La NGLE prefiere distinguir, sin embargo, entre adverbios oracionales (de la enunciación y del enunciado) y conectores discursivos adverbiales (op. cit., $\mathbb{S} \mathbb{S}$ 30.I I-I2) (para el caso de los dos últimos signos citados). (También las interjecciones suelen considerarse clases de palabras de tipo periférico. ${ }^{4}$ ) Así, los ejemplos (I I), (I2) y (I3) reflejan un empleo desviado, respectivamente, de francamente (debería incluir "no", tras pausa, a diferencia de lo que sucede con evidentemente), de obviamente (no se asocia con el tipo de paráfrasis con la que se vincula sinceramente) y de consecuentemente (no puede comparecer autónomamente en el enunciado de una intervención reactiva, en contraste con lo que sucede con honradamente o con ciertamente) $)^{5}$ :

(I I) -Veo que no vendrás al concierto -?Francamente / Francamente, no / Evidentemente

(I2) Sinceramente, Juan no cuenta todo lo que sabe. / Obviamente, Juan no cuenta todo lo que sabe

Soy sincero al decir(te) que Juan no cuenta todo lo que sabe / *Soy obvio al decir(te) que Juan no cuenta todo lo que sabe / Es obvio que Juan no cuenta todo lo que sabe

(I3) -Es una injusticia que no le hayan dado el premio a Pedro -Honradamente, sí / Ciertamente / "Consecuentemente / Consecuentemente, deberíamos hacer un escrito de protesta 
Aun admitiendo como legítimas las razones del gramático para prevenir contra las combinaciones de elementos heterogéneos en las clasificaciones que han de elaborarse en el marco gramatical y, por consiguiente, para proscribirlas, hay que reconocer igualmente que, a menudo, el análisis de elementos sintácticamente heterogéneos puede resultar aceptable e incluso plausible desde otras perspectivas del análisis lingüístico, y esto vale especialmente para el enfoque pragmático. Todo depende del punto de partida del investigador: por ejemplo, y con referencia siempre al español, en un estudio onomasiológico, como el de Barrenechea (I979 [I969]), se presentan unidades morfológica y sintácticamente muy diversas bajo marbetes singularizados desde un punto de vista semántico-pragmático. Y, así, se analizan conjuntamente unidades como verbos performativos o realizativos (creo; me parece, etc.), locuciones adverbiales (en efecto; al parecer, por lo visto, tal vez, etc.) o adverbios (efectivamente, naturalmente; quizás, posiblemente, etc.), como elementos matizadores de la aserción (expresan, según la autora citada -y tal como se ha indicado-, el refuerzo de la aserción, o la suspensión motivada de la aserción-caso de los llamados "adverbios de duda": quizá, tal vez, etc., o de los signos que apuntan hacia la fuente del mensaje: al parecer, por lo visto, etc.-, etc.).

Reconociendo la legitimidad del enfoque onomasiológico para un estudio pragmático, yo he querido situarme, en el presente trabajo, en una perspectiva más ajustada a los criterios más puramente gramaticales, sintácticos: es decir, he prescindido de unidades de tipo enunciativo (como francamente) para centrarme más claramente en un conjunto de signos adverbiales (tanto adverbios como locuciones adverbiales) que se ajustan al estatuto de los llamados adverbios (y locuciones adverbiales) oracionales del enunciado, de modalidad epistémica (cf. Palmer I986), y que refuerzan la aserción, es decir, que entran dentro de lo que la NGLE denomina evidenciales. O sea, me refiero siempre a elementos adverbiales que son disjuncts of attitude, o adverbes de phrase qui expriment la modalité épistemique, o avverbi modali, etc. Precisemos, pues, más las propiedades distribucionales de estos signos.

Los adverbios disjuntos de actitud (o de modalidad) (y las locuciones adverbiales de función semejante), es decir los llamados adverbios oracionales del enunciado, incluyen en su interior subconjuntos numerosos, porque muestran ciertas diferencias de comportamiento en relación, sobre todo, con las paráfrasis que se les asignan (Greenbaum I969: 94). Pero suelen caracterizarse, específicamente, por los siguientes rasgos: a) no alteran el contenido proposicional del segmento del 
discurso que comentan, pues quedan fuera del alcance de la función predicativa de dicho segmento, y, por ello, no les alcanza la negación ni se someten a la interrogación parcial (a diferencia de lo que sucede, por ejemplo, con los adverbios y locuciones adverbiales de tipo adjunto, llamados también adverbios modales o de modo); b) solo suelen combinarse con la modalidad asertiva o declarativa (según hemos comentado ya); y, como hemos indicado también ya: c) pueden desempeñar, solos, con autonomía, un turno de habla, que comenta el enunciado del turno precedente.

Es claro, pues, que dichos signos adverbiales muestran, respecto de a), un comportamiento afín al de las interjecciones, los elementos adverbiales disjuntos de estilo y los signos adverbiales conjuntivos (todos ellos, como indica la NGLE, elementos periféricos). Asimismo, son afines a las interjecciones también en relación con la propiedad indicada en c) (rasgo que los diferencia, en cambio, de los otros dos tipos de elementos adverbiales "oracionales"). Por otra parte, los signos que nos ocupan difieren de las interjecciones, de los elementos enunciativos (disjuntos de estilo) y de los signos conjuntivos en lo referente al rasgo b).

Detengámonos brevemente a recordar ahora las diferencias entre los signos adverbiales de modalidad (o adverbios oracionales del enunciado) y los adverbios adjuntos o de modo (precisadas también por Greenbaum, I969)6. Así, en (I4a), naturalmente se comporta como un adverbio de modalidad: no puede resultar afectado por la negación de la estructura oracional a la que remite, ni puede servir de respuesta a una pregunta de tipo parcial (no funciona como un complemento circunstancial, sino como un complemento de modalidad o un atributo oracional, según ciertos autores: cf. Gutiérrez Ordóñez, I997); mientras que, en ( $14 \mathrm{~b}$ ), naturalmente funciona como un adverbio de modo (o sea, como un adverbio adjunto): se comporta, así, como un complemento circunstancial, y, por ello, puede verse afectado por la negación del predicado verbal de la oración en la que se halla incluido, y servir de respuesta a una pregunta de tipo parcial. Veámoslo:

(I4a) Naturalmente, Juan no ha venido hoy a clase

(I 4a)' "Juan no ha venido hoy a clase naturalmente, sino evidentemente

(I4a)" - ¿Cómo no ha venido hoy Juan a clase?

-*Naturalmente

(I 4 b) Juan se expresa naturalmente

(I4b)' Juan no se expresa naturalmente, sino afectadamente

(I 4 b)" - ¿Cómo se expresa Juan?

-Naturalmente. Sin ninguna afectación. Con naturalidad 
De modo análogo, la locución adverbial sin duda (con alguna variante como sin duda alguna) se comporta como un adverbio oracional del enunciado (un adverbio de modalidad) en ( $5_{5}$ a), mientras que el sintagma preposicional sin $d u d a$ (con muchas más posibilidades de variación), en ( ${ }_{5}$ b), muestra el comportamiento característico de un adverbio adjunto, pues funciona como un complemento circunstancial:

(I 5a) Sin duda / Sin duda alguna, Esther ha estudiado mucho

(I 5a)' "Esther no ha estudiado sin $d u d a / \sin d u d a$ alguna, sino con inseguridad

(I 5a)" - ¿Cómo ha estudiado Esther?

-*Sin $d u d a$

( 5 b) Esther me respondió sin (ninguna) duda / sin dudas / sin dudarlo / sin duda de ningún género

( $\mathrm{s}$ b)' Esther no me respondió sin dudas / sin dudar, sino con vacilaciones / con inseguridad

( 5 b)" - ¿Cómo te respondió Esther?

-Sin dudas / Sin dudar

Establecidas -y destacadas- las diferencias de tipo sintáctico entre los signos adverbiales de modalidad y los de modo (disjuntos y adjuntos, respectivamente), ha de reconocerse, con todo, que no siempre es fácil determinar la frontera distribucional que existe entre unos y otros elementos (si bien es cierto que es más restringido el conjunto de los primeros que el de los segundos, al caracterizar aquellos un enunciado -un acto de habla asertivo, habitualmente-, y estos, en cambio, un conjunto de procesos verbales de variadas posibilidades significativas). El siguiente ejemplo, tomado de un texto de Julián Marías, permite ilustrar lo que intento exponer:

(16) La actitud de incomprensión frente a la existencia de lenguas distintas del español (pero tan españolas como él), la suspicacia frente a su uso, la voluntad de estorbarlo, a veces el más tosco desdén, todo ello, lejos de resolver el "problema" -si es que en realidad hay un problema-, lo ha agudizado hasta el punto de que hoy evidentemente lo es ( $\mathrm{y}$, sobre todo, lo será mañana). (Julián Marías, La España real, 44)

En el ejemplo precedente, el signo evidentemente puede ajustarse a las dos categorías (y las correspondientes funciones) que venimos distinguiendo. De una parte, evidentemente puede reflejar un adverbio de modo o de manera -complemento circunstancial de "es"-, pues podemos parafrasearlo como "de forma evidente", "de modo palpable", 
"con toda evidencia", etc., y podemos también desplazar el signo en el cotexto: "hoy evidentemente lo es", "hoy lo es evidentemente", subrayando el valor modal, sin ninguna pausa. Pero, de otro lado, en (I6), evidentemente puede expresar también un comentario valorativo de Marías, como adverbio de modalidad, en el sentido de que su aserto "la incomprensión frente a la existencia de lenguas distintas del español es hoy un problema"- se fundamenta en una deducción o en una percepción de evidencia, es decir, no admite duda, se impone como algo evidente. La ausencia de comas favorece la ambigüedad semántica aducida y comentada. Es claro que, en cuanto adverbio de modalidad, evidentemente matizaría la aserción, reforzándola.

Desde el punto de vista sintáctico, pues, los signos adverbiales que nos ocupan se ajustan a las propiedades distribucionales de los disjuntos de actitud ( $c f$. Greenbaum I969; Dik I997, etc.) o de los llamados adverbios oracionales del enunciado ( $c f$. NGLE), de modalidad epistémica (de índole evidencial) ( $c f$. Palmer, I986), una de cuyas funciones semántico-pragmáticas más importantes consiste en reforzar la aserción (cf. Barrenechea I979 [I969]). Dicha función semántico-pragmática deriva de las propiedades semánticas de los signos adverbiales de que tratamos, las cuales resultan especialmente sugestivas para el análisis lingüístico de los elementos que estudiamos. Vamos a ocuparnos de ellas a continuación ${ }^{7}$.

\section{Propiedades semánticas}

En primer término, tratando de responder a la primera cuestión que hemos planteado supra, en el $\mathbb{S}$, debemos abordar el tipo de significado que reflejan los signos adverbiales de modalidad epistémica que analizamos. De acuerdo con el enfoque relevantista predominante en los años 90, los disjuntos actitudinales no forman parte de la descripción de los marcadores del discurso (MD), ya que su significado no es, según los autores aludidos, de procesamiento, sino conceptual (aunque los signos adverbiales de modalidad se ajustan a otra propiedad semántica de los MD: no modifican las condiciones de verdad de los elementos que comentan). Suele fundamentarse tal punto de vista en las paráfrasis con las que se vinculan los signos adverbiales que nos ocupan. Compárese, así, el ejemplo (I7) con el (I 8), que contiene la paráfrasis del que le precede:

(I7) Obviamente, ya no viene al cine

(I8) Es obvio que ya no viene al cine 
Sin embargo, no parece sostenible tal propuesta: a) porque muchos otros MD incluidos habitualmente entre los conectores adverbiales (prototípicamente $\mathrm{MD}$, pues) muestran contenido tan conceptual como el de los adverbios disjuntos (me refiero especialmente a los llamados reformuladores de conclusión o síntesis: v. gr., en resumen, en sintesis, en conclusión, en suma, etc., que se ajustan al estatuto de los disjuntos de estilo o adverbios oracionales enunciativos) (lo cual ha sido reconocido por varios estudiosos, e incluso desde la propia teoría mencionada: véase Martín Zorraquino 20ıob); b) porque el valor de los adverbios disjuntos no es equivalente al de la paráfrasis con que se los vincula (cf. Bellert 1977), como vamos a intentar mostrar. En otras palabras, lo que quiero decir es que los signos de que tratamos orientan sobre el procesamiento de la información, al contextualizar de forma específica el segmento de discurso al que remiten, y, al mismo tiempo, presentan, en parte, rasgos semánticos afines a los de la base léxica, conceptual, que reflejan o con la que guardan relación (cf. Martín Zorraquino \& Portolés Lázaro I999; Torner 2007).

A diferencia, sin embargo, de un sustantivo -denotador de una entidad, con un conjunto de propiedades específicas- o de un adjetivo -denotador, a su vez, de una cualidad-, los adverbios de modalidad constituyen semánticamente, según se viene mostrando en la bibliografía, marcos o universos -mundos- que le sirven al locutor para comentar, valorándolo o matizándolo, el aserto que emite o que otro interlocutor ha emitido ( $c f$. Molinier \& Levrier 2000; Anscombre 200I; Martín Zorraquino 200I y 20I3, etc. $)^{8}$.

Vamos a tratar de ilustrar lo que vengo exponiendo por medio de un ejemplo que reproduce uno de los comentados en Martín Zorraquino (200I). Cada signo adverbial de modalidad aportado va a ser descrito semánticamente partiendo de una hipótesis interpretativa de su contenido que se verifica a partir de los encadenamientos cotextuales incluidos en cada caso. Comentemos, así, el ejemplo (I9):

(19) A: Ese cuadro está torcido.

B: a. Desde luego. Está ladeado hacia la izquierda

b. Naturalmente. Ha habido un terremoto esta mañana

c. Claro. Se ha caído uno de los clavos que lo sostenían

d. Por supuesto. Y es feísimo

Como leemos, en el ejemplo (r9), el locutor A aserta "Ese cuadro está torcido". Tal opinión es comentada por el locutor B por medio de un signo adverbial de modalidad epistémica que refuerza lo asertado por 
A, si bien, en cada caso (al emplear cada uno de los signos adverbiales, en $a, b, c$ y d), el comentario respectivo encierra, junto a rasgos semánticos coincidentes, algunas propiedades específicas -diferenciadoras-, pues no estamos ante elementos completamente sinonímicos.

En efecto. Todos los signos adverbiales destacados expresan, confirmándolo, lo evidente del contenido asertado por A ("es patente que el cuadro está torcido"), pero, en (a), tal confirmación asertiva se apoya en la propia experiencia del hablante B (de ahí que su discurso continúe, congruentemente, aduciendo algo percibido personalmente por él); en (b), en cambio, lo que el locutor B señala con naturalmente es que el contenido de la aserción de A, siendo evidente, viene fundamentado, desde el punto de vista de B, por una relación natural, de acuerdo con su conocimiento del mundo, entre diversos factores que operan en el contexto de comunicación (en concreto: la modificación posicional de las cosas y los terremotos), por lo que B prosigue su discurso añadiendo el dato de "Ha habido un terremoto esta mañana"; en (c), por su parte, lo que B expresa, por medio del uso de claro, es que lo evidente de lo asertado por A descansa en una relación de causa-consecuencia entre algunos datos convergentes en el contexto de comunicación (en concreto, que los cuadros se tuercen si los clavos que los sostienen se caen; por eso B prosigue con su discurso advirtiendo: "Se ha caído uno de los clavos que lo sostenían"); y, finalmente, en (d), B recalca lo evidente del aserto de A interpretando, además, que dicho aserto presupone algún tipo de juicio de valor que él cohesiona congruentemente en su propio discurso (en concreto: el cuadro torcido produce una impresión negativa y ello se enlaza coherentemente también con las palabras de B: "el cuadro es feísimo").

A su vez, el ejemplo (20) nos va a permitir ilustrar igualmente la forma de significar de los signos adverbiales que venimos analizando. En este caso, compararemos el significado de desde luego con el de sin duda basándonos en lo expuesto en Martín Zorraquino (20 Iоa y 2013). Supongamos que A oye ruido de agua en los cristales; A bien podrá emitir (20a) o (2ob):

(20a) Sin duda, está lloviendo

(2ob) Desde luego, está lloviendo

Pero, de acuerdo con lo que se ha propuesto a propósito del ejemplo (I9) (en el enunciado I9a), con desde luego el locutor basa su comentario en la propia experiencia de aquello que comenta. Por ello, la sucesión propuesta en (20c) es congruente, mientras que la indicada en 
(2od) resulta costosa de comprender, e incluso no aceptable o, mejor, no esperable normalmente en el contexto comunicativo:

(20c) [Se oye ruido de agua] Sin duda, está lloviendo. [El locutor abre la ventana] Desde luego, llueve.

(2od) [Se oye ruido de agua] \#Desde luego, está lloviendo. [El locutor abre la ventana] \#Sin duda, llueve.

Mientras que, con desde luego, el locutor comenta, confirmándolo, el hecho de que esté lloviendo, como algo que se ajusta a lo que él percibe o experimenta, con sin $d u d a$ simplemente presenta tal hecho como algo que, dada la realidad percibida o dados los indicios asumidos, resulta indudable para cualquiera. Es decir, desde luego sirve para comentar como ajustado a la propia experiencia del hablante lo evidente de lo comentado; en cambio, sin duda se emplea para comentar aquello que resulta indudable para un conjunto indeterminado o general de enunciadores evocados en el contexto de comunicación (siguiendo postulaciones de la teoría de la polifonía ducrotiana: cf. Martín Zorraquino, 2013). Por eso, sin duda (no desde luego) puede valer, en ciertos cotextos, por 'seguramente', 'muy probablemente', como en el ejemplo (2I):

(2I) Jugaban en la plaza tantos niños, que, sin duda, había un colegio en sus alrededores 9

¿Qué tipo de significado encierran, pues, los signos adverbiales que nos ocupan? Como he indicado más arriba, y tal y como suele admitirse en muchos estudios sobre el tema, los adverbios y locuciones adverbiales disjuntos de modalidad comentan el contenido proposicional del segmento del discurso al que remiten, y guían sobre las condiciones contextuales del proceso de la comunicación, en concreto sobre la posición doxológica o valorativa del hablante respecto de aquello a lo que este se refiere con el signo adverbial. Como sucede con los adverbios enunciativos o con las interjecciones, con los disjuntos de modalidad, el hablante no describe, sino que reconoce un marco de fundamentación para la verdad de lo que dice (claro, evidentemente, sin duda, por supuesto, desde luego, por lo visto, etc.) o un marco de valoraciones sobre aquello que emite o aquello que asimila en el proceso comunicativo (bien, bueno, afortunadamente, lamentablemente, incorrectamente, injustamente, etc.). Los adverbios disjuntos modales sirven para insertar en mundos o universos de creencias o de valores la posición del hablante en relación con lo que este presenta o comenta en el proceso comunicativo ( $c f$., por ejemplo, Dendale \& Tasmowski 
I994, Anscombre 200I, o Martín Zorraquino 200I; cf. también, por ejemplo, Molinier-Levrier 2000, para el francés o Venier, I986, para el italiano, y véase especialmente Martín Zorraquino, 20I3, y la bibliografía que contiene y comenta).

Tales propiedades semánticas tienen diversas implicaciones de alcance pragmático. Pragmáticamente, los adverbios de modalidad epistémica que refuerzan la aserción o la ponderan valorando, como fuera de toda duda o como cierto, el contenido del segmento del discurso que comentan, producen un efecto metacomunicativo que evita cualquier tipo de discusión ( $c f$. Venier, I986). Como consecuencia de ello se prestan a expresar el acuerdo con el interlocutor y se convierten en herramientas eficaces para la intensificación de la imagen positiva del interlocutor y para crear una interrelación marcada cortésmente de modo positivo, que puede atenuar, a su vez, la actividad verbal que amenaza la imagen negativa del interlocutor (Brown \& Levinson I987; Haverkate 1994).

Ahora bien, por medio de la entonación el hablante puede matizar si su posición es compartida por otros (la ubica en el universo general que el adverbio codifica) o si obedece a un posicionamiento exclusivamente propio (el locutor manipula en ese caso el valor general del adverbio: se apropia de su carácter general, para dar mayor fuerza a su propia opinión o voluntad) ( $c f$. Martín Zorraquino 200I). Así, en el ejemplo (22), $\mathrm{B}$ puede replicarle a A de forma totalmente ajustada a su propio punto de vista (con una entonación similar: cadente e intensiva), o, más bien, de modo algo divergente, por medio de una entonación más o menos discordante (suspensiva), que, indicando menor aquiescencia, exprese grado distinto de entusiasmo o convicción, etc.:

(22) A: ¡A una madre no se la desobedece jamás!

B: ¡Naturalmente! / Naturalmente...

De modo parecido, en (23), A puede tratar de buscar la connivencia de B por medio de un claro suspensivo, con el que insinúa como evidente el aserto que comenta, o puede, más bien, imponer dicho aserto con un claro contundente. A su vez, B puede confirmar el punto de vista de A coincidiendo con él, por medio de una entonación expresivamente concordante, o B puede mostrar un punto de vista divergente mediante una entonación discordante con la de A:

(23) A: Ustedes, claro..., / ;claro!, después de un viaje tan largo, estarán cansados 
B: I) Claro [agradeciendo la amable suposición de A]. 2) ¡Claro, claro!! [asegurando como indudable el cansancio y tratando de evitar, por tanto, por ejemplo, cualquier insinuación posterior que implique esfuerzo por parte de B] / I) Claro... [marcando, por ejemplo, como algo impositiva la intervención de A]. 2) ;Claro! [coincidiendo plenamente con $\mathrm{A}]^{\text {Io }}$

Y, de otra parte, la proyección pragmática de los signos adverbiales que estamos analizando varía, asimismo, en función del elemento concreto que utilicemos (claro o naturalmente o desde luego o evidentemente, etc.). La unidad seleccionada por el locutor refleja, en cada caso, la fundamentación perceptiva o deductiva en que este basa lo evidente del aserto que comenta, orientando, así, dentro del contexto comunicativo, sobre la posición doxológica que él adopta en función de los diversos factores que operan en este (el destinatario o destinatarios posibles; lo dicho anteriormente, etc.). Por ello, en el ejemplo (24) resultaría raro que el locutor B comentara con evidentemente lo expuesto por A (la muerte de la madre de María), valorando el sufrimiento de la señora aludida, puesto que difícilmente pueden evocarse elementos que hagan perceptible o deducible dicho sufrimiento; en cambio, el empleo de ciertamente es sintomático de la certidumbre de $\mathrm{B}$ (como compartible, además, por cualquiera, en particular por $\mathrm{A}$, destinatario de la réplica de $\mathrm{B}$ ) sobre los padecimientos de la señora aludida antes de morir:

(24) A: Ha muerto la madre de María

B: Ciertamente, la pobre señora sufrió mucho. / \#Evidentemente, la pobre señora sufrió mucho

En cambio, en (25), el segundo enunciado emitido por A permite convocar en el contexto datos que llevan a experimentar o a deducir a B (y a cualquiera) que el sufrimiento de la madre de María fue intenso, por lo que lo comenta con evidentemente:

(25) A: Ha muerto la madre de María. Se le declaró una peritonitis aguda la semana pasada

B: Evidentemente, la pobre señora ha tenido que sufrir mucho

A su vez, es claro que en (25), por motivos análogos a los aducidos para (24), el locutor B podría haber empleado también ciertamente para comentar lo dicho por A:

(25)' A: Ha muerto la madre de María. Se le declaró una peritonitis aguda la semana pasada

B: Ciertamente, la pobre señora ha tenido que sufrir mucho 
Y, volviendo a (24), por razones parecidas a las aportadas para (25), B podría haber utilizado evidentemente, con toda naturalidad, para comentar el enunciado al que remite, ya que el contexto comunicativo permite, en este caso, deducir el contenido de dicho enunciado (la muerte de una madre es normalmente muy dolorosa para los hijos):

(24)' A: Ha muerto la madre de María

B: Evidentemente, María estará pasándolo muy mal ${ }^{\mathrm{II}}$

Llegados a este punto, debemos recordar la segunda pregunta que hemos planteado supra, en el $\mathbb{S}$ I: ¿qué afinidades y diferencias existen entre los signos adverbiales que nos ocupan y aquellos adjetivos cuya base léxica comparten? (O sea, entre ciertamente / cierto; evidentemente / evidente, etc., cuando unos y otros se emplean para comentar o valorar un segmento del discurso).

A mi juicio, es semánticamente diferente lo que se dice por medio de un adverbio de modalidad y lo que se dice a través de un adjetivo calificativo parentético, destacado ( $c f$. Martín Zorraquino 20Iob): el signo adverbial es, puesto que evoca un marco o mundo de creencias o de valores, polifónico; el adjetivo, en cambio, remite a un solo locutor. Por ejemplo, en (26), lo que el hablante comenta con ciertamente no solo deja claro que es cierto el hecho de que "Juan tiene buen corazón", sino que, además, sitúa la certeza en un universo que tanto él como su interlocutor pueden compartir; por ello, el adverbio permite inscribir el comentario del hablante en un marco de certeza del que ambos interlocutores pueden considerarse "propietarios" o "responsables" (la entonación permite regular el grado de participación en la certeza de cada uno de ellos: puede ampliar o restringir la polifonía implicada en el signo adverbial):

(26) A: Juan ha entregado el sueldo de este mes a la UNICEF B: Juan tiene buen corazón, ciertamente

Mientras que, con cierto, el locutor asume la responsabilidad del comentario. Es él el que califica de cierto el que "Juan tiene buen corazón":

(27) A: Juan ha entregado el sueldo de este mes a la UNICEF B: Juan tiene buen corazón. Cierto

Por eso es más esperable que (26) prosiga como en (28) y que (27) prosiga como en (29), y no al revés:

(28) A: Juan ha entregado el sueldo de este mes a la UNICEF

B: Juan tiene buen corazón, ciertamente, porque gestos así no son frecuentes 
(29) A: Juan ha entregado el sueldo de este mes a la UNICEF

B: Juan tiene buen corazón. Cierto. No es la primera vez que hace eso: soy testigo de su generosidad en muchas otras ocasiones

El ejemplo siguiente -(30)-, tomado de los materiales del CREA, permite apreciar la diferencia de significado (y la respectiva proyección pragmática) de ciertamente y cierto:

(30) Digámoslo con toda claridad: la única hegemonía indiscutible de los EE UU, en el mundo actual, es la militar. Ésta es, ciertamente, sustantiva. Si no recuerdo mal, la segunda potencia mundial armamentística tiene un tercio del poder militar de los EE UU. Sin duda, más de un partidario de la realpolitik diría a estas alturas que, efectivamente, los imperios se construyen y mantienen sobre el pilar desnudo del poder, del músculo de las armas. Muy cierto. (Apud CREA, El País, 17.03. 2003)

En el ejemplo precedente, con ciertamente, el periodista pondera y reconoce como conocido, ajustado a la realidad, a la verdad compartida por cualquiera evocable en el contexto, el hecho de que sea sustantiva la hegemonía militar de los Estados Unidos. Mientras que con cierto (intensificado por medio de muy) el periodista, por sí mismo, declara verdadero (y lo describe así), ajustado a su certidumbre, todo lo que ha expuesto en el fragmento de discurso precedente; califica lo dicho como "muy cierto".

\section{Comportamiento discursivo}

Como se suele señalar en todos los estudios que versan sobre los signos de que tratamos, los elementos que venimos analizando pueden ocupar una posición inicial, media o final respecto del segmento de discurso al que remiten (lo destacó ya Barrenechea I979 [I969]). Es decir: o bien preceden al segmento discursivo que comentan (con una pausa entre ambos, marcada normalmente mediante una coma) (cf. supra, v. gr., la réplica de $\mathrm{B}$ en el ejemplo $24^{\prime}$ ); o bien se intercalan (entre pausas, no siempre marcadas por comas) en el interior de dicho segmento, como sucede en el ejemplo (30); o bien ocupan una posición final, precedida de pausa (señalada habitualmente con coma), comentando lo enunciado anteriormente (o, en una réplica, el enunciado que ha emitido el interlocutor que ha hablado previamente), según sucede en el siguiente ejemplo tomado de un texto de Francisco Umbral:

(3I) Así que cuando el escritor cena, decide hacerlo en público, porque lo de menos es la cena, claro. Una gran cena hay que hacerla ante toda la 
literatura española, con su ritual, su pompa y su circunstancia de cena del Tenorio. (Francisco Umbral, La noche que llegué al Café Gijón, $66-67)^{12}$

Aunque el tipo de posición -inicial, media o final- suele vincularse con factores informativos (tema / rema, por ejemplo), lo cierto es que es difícil a menudo asignar un valor definido a la colocación del signo adverbial comentador, pues frecuentemente parece cumplir, más bien, un papel focalizador respecto del fragmento discursivo comentado, que una función asociada a las de tópico / comentario. Barrenechea ( I979 [I969]), por ejemplo, advierte de tal complejidad. No voy a aportar, pues, una respuesta propiamente a la tercera pregunta que he incluido supra, en el $\mathbb{S}$ I del presente trabajo.

Diré solo que la versatilidad distribucional de los signos que estudiamos nos lleva a reflexionar sobre los condicionamientos que impone al discurso la linealidad del significante que, como propiedad esencial del signo lingüístico, destacó Saussure (I9I6) (cf. supra, la última pregunta planteada en el $\mathbb{S}$ I). Tal característica restringe las posibilidades expresivas del locutor y le obliga a encadenar su discurso en una sola dirección. Los incisos, sin embargo, representan un procedimiento interesante para paliar, en parte, tal restricción: aportan comentarios secundarios o complementarios a la línea fundamental de los hechos que el locutor expone, en buena medida porque él es consciente del conjunto de factores que, convergiendo en el contexto comunicativo, gravitan en la propia transacción comunicativa, de suerte que trata de matizar esta, sobre la marcha, a base de signos de distinto estatuto (adverbial, conjuntivo, interjectivo, etc., y a veces también oraciones enteras, etc.), que intercala en el texto, marcando, por medio de pausas, su marginalidad y, al mismo tiempo, su vinculación con lo que les precede o les sigue.

En lo que se refiere a los signos adverbiales que nos ocupan, las consultas que he llevado a cabo, para algunos de ellos, en el CREA (20002004) (referidas a la prensa de España), revelan que la posición inicial (PI) es la segunda más frecuente, precedida por la posición media (PM) -la que arroja cifras más altas- y seguida muy de lejos (en tercer lugar) por la posición final (PF). Hay que advertir, con todo, que no he podido hacer un análisis exhaustivo, pues las consultas resultan especialmente complicadas para la posición media ${ }^{\mathrm{I}}$. Pero, para algunos signos, he podido hacer el recuento para las tres posiciones y creo que el resultado, aunque modesto, es pertinente: las cifras son significativas, como vemos a continuación (la primera cifra indica el número de casos; y la segunda, el de documentos; cuando doy dos cifras entre corchetes, la 
que queda fuera del corchete refleja los casos inequívocos de disjuntos de modalidad identificados; la primera dentro del corchete, el número total de signos encontrados; la segunda dentro del corchete, el número de documentos):

Ciertamente: PI (I 5 / I 5 ); PM (29 [5I / 5I]); PF (2 / 5I)

Verdaderamente: PI ( 5 / 5); PM (I [I I / / 96]); PF (o/ 96)

Evidentemente: PI (32/30); PM (40 [46/49]); PF (3/49)

Obviamente: PI (24/24); PM (49 [5I / 49]; PF (o/49)

Naturalmente: PI (35/35); PM (43/43); PF (o/43)

Desde luego: PI (7I / 68); PM (I37 / I 29); PF (6)

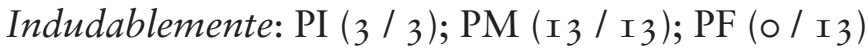

Los datos aportados confirman que la posición final es mucho menos frecuente que la inicial o la intermedia. El desplazamiento, pues, a la derecha (conocido como afterthought) queda preterido en relación con las otras posiciones. Pero no puedo entrar a analizar el interesante ámbito de los llamados "margen izquierdo" y "margen derecho" de la periferia en el discurso.

Los datos para la prensa mexicana, y para los mismos años, muestran tendencias parecidas cuantitativamente: por ejemplo, en PI, ciertamente arroja 6 casos en 6 documentos; verdaderamente, 0 ; obviamente, 6 / 6; evidentemente: 3 / 3; naturalmente: 6 / 6; claro: 2 I / I9; desde luego: 2 I / I 8; sin duda: I9 / I7; indudablemente: 5 / 5; por supuesto: 7 / 7. Y es interesante observar que, en Argentina, apenas se usa desde luego (si bien se detecta en el ejemplo 32) y, en cambio, se emplea desde ya, tanto con valor de adjunto (ejemplo 33), como con valor de locución adverbial de modalidad epistémica (ejemplo 34):

(32) Y, desde luego, una investigación que desemboque en la pérdida del trabajo realizado por las personas, no concuerda con ninguna de las corrientes filosóficas. (Apud CREA, Clarín, I6.07.2003)

(33) Lo que hay que promover desde ya es el abandono de esa megacampaña que nos transporta a la Tribu de los Brady. (Apud CREA, Clarín, I 2.03.2004)

(34) Tiene muchas características que nos hacen presumir que no se trata de un juguete: una funda renovada [...], flash incorporado, vídeoclips de 30 segundos, una pantalla trasera de cristal líquido, buena resolución [...] y, desde ya, un precio de 300 dólares. (Apud CREA, Clarín. Suplemento de Informática, I I. I2. 2002) 
Debe destacarse, por último, el sentido (el objetivo argumentativo o simplemente comunicativo) que cumplen los signos que nos ocupan en el conjunto discursivo en el que aparecen. Insisto en que los elementos analizados sirven fundamentalmente para reforzar la aserción (en el caso de los signos que destacan lo evidente) o para ponderarla (se trata, más bien, de los signos que enfatizan la certidumbre: ciertamente, verdaderamente $)^{\mathrm{I}}$. Pero, en la construcción del discurso, se emplean, con ese valor, para otros objetivos: por ejemplo, para justificar la conclusión en un conjunto argumentativo de tipo ilativo-consecutivo (ejemplo 35), o para destacar el primer elemento de una construcción adversativa, marcando una concesión representada por el miembro que precede a pero (y con el que el locutor sale al paso, concediendo la razón de antemano, a un argumento que imagina que el interlocutor podría proponer $)^{15}$ :

(35) Daba envidia viajar en estas fechas por el resto del mundo y ver el esplendor luminoso de los Campos Elíseos, o asomarse a las pantallas del cine y la televisión para descubrir que había otras formas de anunciar un tiempo de fiestas [...]. Este año las cosas han cambiado y, ciertamente, los madrileños podemos disfrutar de un gran salto en el tiempo. (Apud CREA, La Razón, 02.09.2002)

(36) El evento más importante en la Zaragoza de I 908 fue la Exposición Hispano-Francesa. Pudo haber otras actividades importantes, desde luego [ciertamente / evidentemente / sin duda / naturalmente / ...], pero la Exposición marcó la vida y el desarrollo de la ciudad de forma determinante. (E. Fernández Clemente, Aragón en el siglo XX, Zaragoza, Librería General, 2002, I23)

\section{Conclusión}

En síntesis, las propiedades sintácticas que caracterizan al paradigma de unidades que hemos analizado son las siguientes: se trata de signos adverbiales disjuntos actitudinales, de modalidad epistémica (Greenbaum, I969), que, de acuerdo con los rasgos de tal clase de palabras, pueden acompañar a enunciados de estructura sintáctica diversa, pero especialmente de tipo oracional y de modalidad asertiva, siempre en posición periférica (destacada suprasegmentalmente entre pausas), o que pueden comparecer aislados constituyendo un enunciado autónomo (por ejemplo, en una intervención dialogal reactiva).

Desde el punto de vista semántico estos signos constituyen marcos o universos desde los que el locutor comenta lo que aserta, 
fundamentando su opinión o visión perceptiva como inscrita en dichos marcos. Los signos analizados se caracterizan, en concreto, por expresar la modalidad epistémica (doxológica), presentando la verdad del enunciado al que remiten como claramente evidente, es decir, fuera de toda duda. Por lo que se prestan, desde el punto de vista pragmático, a reforzar la aserción, y, en el discurso, a reforzar la argumentación, lo que implica, de otro lado, otras propiedades pragmáticas relacionadas con el acuerdo y la toma de postura por parte del hablante respecto del interlocutor (Martín Zorraquino 200I, 2003, 2010a y b).

Para la construcción del discurso, los elementos estudiados pueden ocupar tres clases de posición respecto del segmento que comentan: inicial, media y final. La más frecuente es la media y la menos frecuente (con mucho), la final. Las tres posiciones guardan relación con factores informativos que no hemos dilucidado, pero que se hallan vinculados, tanto con conceptos como tema / rema y tópico / comentario, como con el de foco o función focalizadora, así como con los ámbitos informativos tan sugestivos actualmente del "margen izquierdo" o del "margen derecho" incidentales. En todo caso, la versatilidad distribucional de las unidades estudiadas constituye una muestra de los procedimientos de que se vale la lengua para paliar la restricción semiótica que impone la linealidad del significante como propiedad saussureana del signo lingüístico. De otra parte, dicha versatilidad está también al servicio de la construcción del discurso para establecer conclusiones argumentativas, contraargumentativas, concesivas, etc., especialmente relevantes.

Quisiera destacar, en fin, que la utilización de unos u otros signos adverbiales del tipo aquí analizado puede ser un indicio también de la actitud subjetiva, la visión de la realidad y la propia personalidad del hablante. Así, por ejemplo, frente a la joven estudiosa María Antonia Martín Zorraquino, que, en Las construcciones pronominales en español. Paradigma y desviaciones (Madrid, Gredos, 1979), utiliza, con valor pragmáticamente concesivo, naturalmente, por supuesto, evidentemente, etc., en cinco ocasiones, en sus cuatro páginas liminares, el profesor Ignacio Bosque no echa mano de dichos signos adverbiales en las primeras treinta páginas de Las categorías gramaticales (I989). Probablemente, la joven lingüista que escribió el libro editado en 1979 se hallaba cercada, en su imaginación, por las posibles objeciones de los sabios lingüistas que -lo esperaba- iban a leer su libro, y trataba, por ello, de hacer frente, concediendo de antemano su validez, a las previsibles observaciones aludidas. 


\section{Notes}

I. El presente trabajo se inscribe dentro de los estudios realizados por el Grupo de Investigación Consolidado Pragmagrammatica Peripheriae, subvencionado por el Gobierno de Aragón y por el Fondo Social Europeo (código H-029). Forma parte especialmente de todo un conjunto de contribuciones dedicadas al análisis de los signos adverbiales de modalidad (tanto de la enunciación como del enunciado), cuyo objetivo último es ofrecer un diccionario de palabras modales del español, principalmente de estatuto adverbial e interjectivo. Las referencias citadas son las más relevantes en relación con el tema tratado aquí, pero recuerdo al lector que otros investigadores del Grupo mencionado (en particular, Margarita Porroche Ballesteros, José Laguna Campos, Juan Manuel Cuartero Sánchez, Verónica Edeso Natalías, Carmen Solsona Martínez, Carlos Meléndez Quero y Elisa González Ramos) y yo misma, nos hemos ocupado de las partículas de modalidad (adverbios, locuciones adverbiales, interjecciones, etc.), desde la perspectiva sincrónica y desde el punto de vista diacrónico (por ejemplo, los procesos de lexicalización y de gramaticalización que les afectan), en otros trabajos, recogidos, en buena parte, en DIALNET, y de los que incluyo algunos de los más representativos en la bibliografía final.

2. Obsérvese que a menudo se denomina a todos los adverbios de que tratamos "adverbios oracionales", a pesar de que, como hemos mostrado, puedan afectar a segmentos discursivos no oracionales (no verbales) (cf. supra, ejemplos I' a 6'). Ello se debe, sin duda, a que se intenta subrayar su carácter extrapredicativo y al hecho de que estos adverbios pueden afectar a un enunciado de estructura oracional y no solo a un sintagma verbal, o a un adjetivo, o a otro adverbio.

3. Afortunadamente, el adverbio ha dejado de ser "le parent pauvre" del que hablaba Moignet (I963) en los años sesenta del siglo pasado (cf., asimismo, López García-Molins, I977, y Wotjak, I996: VII). Es una categoría que refleja muy bien cómo puede avanzar nuestra disciplina -la lingüística y, más concretamente, la gramática- introduciendo "unidades nuevas que permitan [...] progresar en la competencia del objeto de estudio" (Bosque I989: I 5): en efecto, a partir de toda una serie de contribuciones sobre el adverbio, publicadas desde fines de los años sesenta, sobre el inglés y sobre muchas otras lenguas, en particular, las románicas, esta clase de palabra ha dejado de ser un "cajón de sastre", marbete con el que tantos gramáticos la han etiquetado ( $c f$., por ejemplo, las referencias bibliográficas citadas, más adelante, en la n. 8).

4. Y dicha postura es pertinente (y explicable), porque el objetivo de la Real Academia Española, en la NGLE, es esencialmente gramatical. Como recuerda Ignacio Bosque (1989: 19-20), igual que un estudiante de medicina o un estudiante de arquitectura no pueden conformarse con saber "lo que es" un elemento que están estudiando, sino que tienen que ser capaces de dar cuenta 
de "cómo funciona", y prever que, si se dan determinadas condiciones en el empleo del mismo, puede producirse una catástrofe (por ejemplo, la muerte del paciente sometido a tratamiento o el derrumbamiento de la casa que pretende construirse), también un gramático debe saber que, si se empeña en usar un adverbio enunciativo como si fuera un adverbio del enunciado o como si se tratara de un adverbio de tipo conjuntivo o conectivo, pueden producirse errores lamentables en la construcción lingüística.

5. Las desviaciones detectadas a continuación, en el texto, muestran sendos conjuntos de desajustes respecto de las propiedades a) de los adverbios enunciativos (estos requieren la presencia de sí / no habitualmente en las intervenciones reactivas; admiten paráfrasis vinculadas con la primera persona -a veces también con la segunda persona-, porque remiten -califican- a un verbo realizativo del 'decir' - digo / di- en primera o segunda persona; pueden constituir una intervención o un turno autónomamente -seguidos habitualmente de sí / no-); b) de los adverbios del enunciado (los cuales pueden constituir una intervención reactiva de forma totalmente autónoma y admiten paráfrasis en tercera persona, de sentido impersonal o generalizador, porque, como veremos, proporcionan un cuadro o un marco universal de valoración epistémica); y c) de los adverbios conjuntivos (estos no comparecen en una intervención reactiva de forma autónoma, porque ponen en relación dos segmentos del discurso: conectan explícitamente dos fragmentos textuales).

6. No hace falta insistir en que se trata de propiedades que también distinguen a los adverbios adjuntos de las interjecciones, los adverbios enunciativos y los adverbios conjuntivos.

7. Los signos adverbiales de modalidad epistémica han recibido atención intensa en los últimos treinta años. No puedo dejar de destacar aquí, para el español, las aportaciones de Kovacci (I986 y I999), Fuentes Rodríguez (I99I) -Martín Zorraquino (1994), de hecho, se presenta como una contribución que intenta avanzar en la línea trazada por ambas autoras-, Gutiérrez Ordóñez (I997) (ya citado), Rodríguez Ramalle (2003), Santos Río (2003), Torner (2007), etc. (y aun antes, López García-Molins (1977), que ya se ha citado también). Para otras lenguas románicas, la bibliografía es también copiosa: véanse, por ejemplo, para el francés Borillo (I976) y, sobre todo, Molinier / Levrier (2000), y para el italiano, Venier (I986) (en todos los casos: entre otros muchos títulos).

8. Así, en Martín Zorraquino (2003), abordé el tratamiento lexicográfico de desde luego, como ejemplo de descripción de las propiedades semánticas de la locución y de los sentidos más frecuentes que adquiere en el discurso. En Martín Zorraquino (20I0a) hice algo análogo para sin $d u d a$, al parecer y por lo visto.

9. Obsérvese que resultaría extraño sustituir sin duda por desde luego en el ejemplo (2I). En cambio, desde luego valdría como signo adverbial adecuado 
en el ejemplo (2 I)': “Jugaban en la plaza muchos niños que, desde luego, procedían de un colegio, porque llevaban todos el mismo uniforme”.

Io. La variedad de matices expresivos con que la entonación permite graduar el alcance pragmático de los signos adverbiales que nos ocupan es extraordinariamente rica, tanto si tales signos aparecen en intervenciones iniciativas, como si comparecen en réplicas. En Martín Zorraquino (200I) se incluyen ejemplos con algunas otras unidades (desde luego y por supuesto).

I I. En el ejemplo (24)' sería también posible, por lo expuesto para (24) y para $(25)^{\prime}$, el uso de ciertamente. El empleo de uno u otro signos adverbiales (ciertamente ( evidentemente) es sintomático, de otra parte, según ya he indicado, de la posición doxológica, valorativa, del locutor respecto de aquello que comenta, en función de los factores que convergen en el contexto de comunicación (múltiples y complejos).

I2. En el ejemplo (3 I) Umbral comenta con claro, destacándolo -confirmándolo- como algo evidente, fuera de toda duda, el hecho de que, en el mundo de los escritores, cenar (ingerir alimentos de noche) es lo menos importante, y ello porque, tal y como se percibe y se sabe habitualmente (es lo que desvela claro), lo que los escritores buscan es ser vistos en público y no tanto alimentarse. Por eso, el escritor prosigue su discurso explicitando la conexión de contenidos que ha tratado de subrayar con claro: "Una gran cena hay que hacerla ante toda la literatura española, con su ritual, su pompa y su circunstancia de cena del Tenorio".

I3. En posición inicial, incluyendo en la consulta la coma detrás del signo adverbial, es fácil identificar y contar los casos inequívocos de los disjuntos de modalidad epistémica. Pero, en posición media, es muy laborioso separar los casos de disjuntos de modalidad de los de adjuntos de modo (frecuentemente aquellos no van destacados por comas). Por otra parte, los ejemplos en posición final (precedidos de coma) suelen ser muy escasos.

I4. Barrenechea (I979 [I969]) distingue los signos que refuerzan la aserción (desde luego, claro, evidentemente, naturalmente, indudablemente, sin duda, efectivamente, en efecto, por supuesto) de los que la ponderan (ciertamente, verdaderamente, realmente, en realidad). No he podido entrar en tal distinción, que es muy fina y pragmáticamente pertinente. Los primeros elementos se integran en marcos o universos que expresan lo evidente (comentan algo cuyo contenido se siente impuesto como tal a través de los sentidos o de la experiencia perceptiva); los segundos, en cambio, se integran en marcos vinculados con la certeza o la certidumbre, experiencia más interiorizada por parte del locutor. Es interesante observar (y no me he ocupado de ello en el presente estudio; sí lo he hecho en Martín Zorraquino, I994, y lo hemos tenido en cuenta en Martín Zorraquino \& Portolés Lázaro, I999), que el primer grupo de unidades suele poder combinarse con que (por ejemplo: ;claro, evidentemente, naturalmente, por supuesto, sin duda, indudablemente que lo sabe!), mientras que el segundo es, 
tal vez, menos proclive a dicha construcción (?ciertamente, verdaderamente, realmente que lo sabe).

I 5. El sentido concesivo que pueden aportar los signos adverbiales que nos ocupan es particularmente interesante, porque pone de relieve, a menudo, un discurso polifónico: el locutor actúa como un enunciador que sale al paso de lo que cree que podría objetar un posible interlocutor en el contexto comunicativo ( $c f$. Martín Zorraquino, 20I3, que comenta el análisis ducrotiano de certes). Dicho sentido concesivo en los signos adverbiales analizados viene ampliamente destacado en Martín Zorraquino / Portolés Lázaro (I999); cf. igualmente, Martín Zorraquino (200I, 2010a y 20I3).

\section{Referencias}

\section{Textos citados para los ejemplos analizados}

Marías, Julián. I976. La España real. Madrid: Espasa-Calpe.

Real Academia Española. Banco de datos (CREA) [en línea]. Corpus de referencia del español actual. http://www.rae.es [Consultas realizadas entre el I6.04.20I2 y el I8.05.20I2]

Umbral, Francisco.ı980. La noche que llegué al Café Gijón. Barcelona: Destinolibro. (Primera ed.: Barcelona, Edics. Destino, I977).

\section{Monografías y artículos citados}

Anscombre, Jean-Claude. 200I. "A coup sûr / Bien sûr: des différentes manières d'être sûr de quelque chose”. In: Depuy-Engelhardt, Hiltraud, Silvia Palma, Jean-Emmanuel Tyvaert (eds.). Les phrases dans les textes. Les sons et les mots pour les dire. Les connecteurs du discours. L'opposition verbonominale en acte. Reims: Presses Universitaires de Reims. I35-I60.

Barrenechea, Ana María.r979 [I969]. "Operadores pragmáticos de actitud oracional: los adverbios en -mente y otros signos”. In: Estudios lingüísticos $y$ dialectológicos. Buenos Aires: Hachette. 39-59.

Bellert, Irena.I977. “On semantic and distributional properties of sentential adverbs". Linguistic Inquiry, 8 / 2. 32 I-347.

Borillo, Andrée. I976. "Les adverbes et la modalisation de l'assertion”. Langue fran-çaise, 30. 74-89.

Bosque, Ignacio. I989. Las categorías gramaticales. Madrid: Síntesis.

Brown, Penelope \& Stephen Levinson. 1987. Politeness: Some universals in Language Usage. Cambridge: Cambridge University Press (2. ${ }^{a}$ ed.; I. ${ }^{a}$ ed., I978). 
Cuartero Sánchez, Juan Manuel. 20II. "Notoriamente y otros adverbios modales de valoración epistémica”. Español Actual, 96. 4I-6I.

Dendale, Patrick \& Liliane Tasmowski.I994: "Présentation”. Les sources $d u$ savoir. Langue Française, I02. 3-7.

Edeso Natalías, Verónica. 2009. Contribución al estudio de la interjección en español. Bern: Peter Lang.

Fuentes Rodríguez, Catalina. I99I. “Adverbios de modalidad”. Verba, I 8. 275-32I.

González Ramos, Elisa. 2005. "Cómo eludir responsabilidades sobre lo dicho: los signos 'por lo visto' y 'al parecer' (analogías y diferencias en su empleo actual)". Español Actual, 84. I 53-I 58.

Greenbaum, Sidney. I969. Studies in English Adverbial Usage. Londres: Longman.

Gutiérrez Ordóñez, Salvador. I997. "Complementos de verbo enunciativo y atributos de modalidad”. In: Gutiérrez Ordóñez, Salvador. La oración y sus funciones. Madrid: Arco / Libros. 343-367.

Haverkate, Henk. I994. La cortesía verbal. Madrid: Gredos.

Jackendoff, Ray. I972. Semantic Interpretation in Generative Grammar. Cambridge: MIT Press.

Kovacci, Ofelia.ı986. "Notas sobre adverbios oracionales: dos clases de limitadores del dictum”. Revista Argentina de Lingüística, 2. 299-3 I 6.

Kovacci, Ofelia. I999. “El adverbio”. In: Bosque, Ignacio \& Violeta Demonte (dirs.). Gramática descriptiva de la lengua española. Madrid: Espasa-Calpe, vol. I. 705-786 (esp. 760-763).

López García-Molins, Ángel.r977. Elementos de semántica dinámica: semántica española. Zaragoza: Pórtico.

Martín Zorraquino, María Antonia. I993. “Algunas observaciones sobre claro como operador pragmático en español actual”. In: Gerold Hilty (ed.). Actes du XXème. Congrès International de Linguistique et Philologie Romanes, I. Tübingen-Basel: Francke. 467-478.

Martín Zorraquino, María Antonia.I994. "Sintaxis, semántica y pragmática de algunos adverbios oracionales asertivos". In: Violeta Demonte (ed.). Gramática del español. México, El Colegio de México. 557-590.

Martín Zorraquino, María Antonia. 200I. "Remarques sur les marqueurs de modalité, l'expression de l'accord et la prise de position du locuteur". In: Depuy-Engelhardt, Hiltraud, Silvia Palma \& Jean-Emmanuel Tyvaert (eds.). Les phrases dans les textes. Les sons et les mots pour les dire. Les 
connecteurs $d u$ discours. L'opposition verbo-nominale en acte. Reims: Presses Universitaires de Reims. I83-202.

Martín Zorraquino, María Antonia. 2003. "Marcadores del discurso y diccionario: sobre el tratamiento lexicográfico de desde luego". In: Echenique Elizondo, María Teresa \& Juan Sánchez Méndez (coords.). Lexicografía y lexicología en Europa y América. Homenaje a Günther Haensch, MadridValencia: Gredos / Biblioteca Valenciana. 439-452.

Martín Zorraquino, María Antonia. 20гоa. "Las partículas discursivas en los diccionarios y los diccionarios de partículas discursivas (con referencia especial a desde luego / sin duda y por lo visto / al parecer)". In: Bernal, Elisenda, Sergi Torner \& Janet DeCesaris (eds.). Estudis de Lexicografia 2003-2005. Barcelona: IULA. 23 I-357.

Martín Zorraquino, María Antonia. 20 o ob. "Los marcadores del discurso y su morfología”. In: Loureda Lamas, Óscar \& Esperanza Acín Villa (coords.). Los estudios sobre marcadores del discurso en español, hoy. Madrid: Arco / Libros. 93-I $8 \mathrm{I}$.

Martín Zorraquino, María Antonia. 2013. "La polifonía en algunos signos adverbiales disjuntos que matizan la aserción en español actual (desde luego y sin duda; por lo visto y al parecer)". In: Gévaudan, Paul, Vahram Atayan \& Ulrich Detges, Modalität und Polyphonie. Modalité et polyphonie. Modalidad y polifonía. Tübingen: Stauffenburg-Verlag. 99-I 26.

Martín Zorraquino, María Antonia \& Portolés Lázaro, José.I999. "Los marcadores del discurso". In: Bosque, Ignacio \& Violeta Demonte (dirs.). Gramática descriptiva de la lengua española. Vol. 3. Madrid: Espasa-Calpe, $405 \mathrm{I}-42 \mathrm{I} 3$.

Meléndez Quero, Carlos. 20 I I. Los adverbios disjuntos de valoración emotiva en español actual. (2 vols.) Saarbrücken: Editorial Académica Española.

Moignet, Gérard. I963. "L'incidence de l'adverbe et l'adverbialisation des adjectifs". Travaux de Linguistique et de Littérature, I. Strasbourg. I75-I94.

Molinier, Christian \& Françoise Levrier. 2000. Grammaire des adverbes. Description des formes en -ment. Genève: Librairie Droz.

Porroche Ballesteros, Margarita. 2005. "Sobre los adverbios enunciativos españoles: caracterización, clasificación y funciones pragmáticas y discursivas fundamentales”. Revista Española de Lingüística, 35 / 2. 495-522.

Porroche Ballesteros, Margarita \& Laguna Campos, José. 20 I I. "El acuerdo y el desacuerdo. Los marcadores discursivos bueno, bien, vale y de acuerdo". Español Actual, 96. I 59-I79.

Palmer, Frank.r986. Mood and modality. Cambridge: Cambridge University Press. 
Real Academia Española y Asociación de Academias de la Lengua Española. 2009. Nueva Gramática de la Lengua Española. Morfología y sintaxis. Sintaxis II, 2 vols. Madrid: Espasa, (esp., cap. 30; pp. 2344-2370).

Rodríguez Ramalle, Teresa María. 2003. La gramática de los adverbios en-mente o cómo expresar maneras, opiniones y actitudes a través de la lengua. Madrid: Universidad Autónoma de Madrid.

Santos Río, Luis. 2003. Diccionario de partículas. Salamanca: Luso-Española de Ediciones.

Saussure, Ferdinand.r946 [19г6]. Curso de lingüistica general. Buenos Aires: Losada, (trad. al esp. de Amado Alonso).

Sperber, Dan \& Deirdre Wilson.I986. Relevance. Communication and cognition. Oxford: Blackwell.

Solsona Martínez, Carmen. 20ri. "Funciones discursivas del marcador insomma en la enseñanza del italiano L2 a hispanohablantes". Cuadernos de Filología Italiana, I 8. 45-74.

Torner Castells, Sergi. 2007. De los adjetivos calificativos a los adverbios en -mente: semántica y gramática. Madrid: Visor Libros.

Venier, Federica. I986. "Gli avverbi modali". Lingua e stile, XXI/4. 459-483.

Wotjak, Gerd (ed.).I996. En torno al adverbio y los circunstanciales. Tübingen: Narr. 